\title{
Changes in the components of the diffusing capacity in pulmonary sarcoidosis
}

\author{
NEILA. J . HAMER ${ }^{1}$ \\ From the Medical Unit, King's College Hospital, London, S.E.5
}

Previous studies in pulmonary sarcoidosis have demonstrated that impairment of the diffusing capacity is the most frequent abnormality of pulmonary function in this condition (Marshall, Smellie, Baylis, Hoyle, and Bates, 1958). The work of Roughton and Forster (1957) showed that the diffusing capacity could be divided into two components: one involves the transfer of oxygen through the alveolar-capillary membrane, and the other its combination with haemoglobin in the red cells of the lung capillaries (Fig. 1). The present study was undertaken to determine the effect of pulmonary sarcoidosis on these two factors.

Carbon monoxide may be used to determine the diffusing capacity as it behaves in the same way

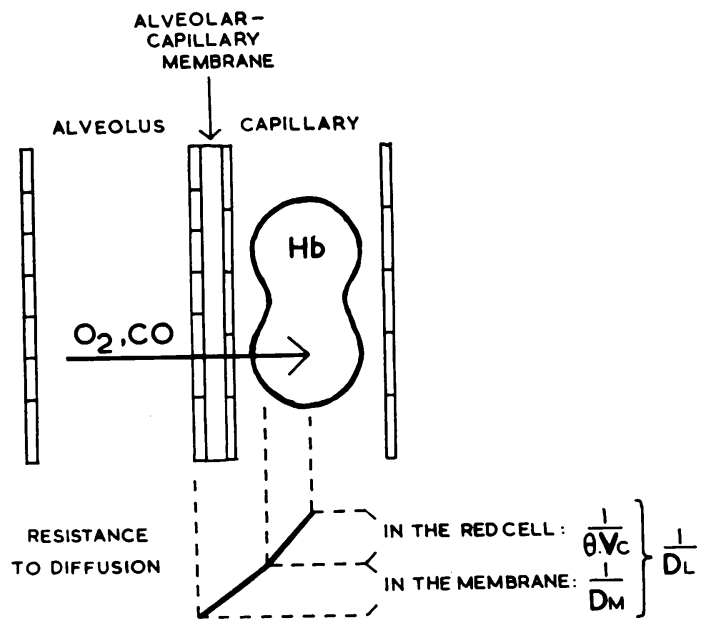

FIG. 1. Diagrammatic representation of diffusion in the lung. Oxygen or carbon monoxide diffuse across the alveolar-capillary membrane and combine with haemoglobin in the pulmonary capillary red cells. The competition between the two gases for the available haemoglobin can be used to separate the membrane and the red cell components of the diffusing capacity.

1 Present address: The Institute of Cardiology, 35 Wimpole Street, London, W.1 as oxygen. Roughton and Forster (1957) showed that oxygen and carbon monoxide compete for the available haemoglobin in the pulmonary capillaries, so that an increase in oxygen tension reduces the uptake of carbon monoxide. As this effect is confined to the red cell it can be used to separate the two parts of the diffusion process. Diffusion of carbon monoxide through the alveolar-capillary membrane is unaffected by variations in oxygen tension.

The alveolar-capillary membrane and the pulmonary capillary red cells may be regarded as forming two consecutive resistances to the transfer of gas from the alveoli to the blood stream. The sum of these two components forms the overall resistance to diffusion, which is the reciprocal of the diffusing capacity $\left(\frac{1}{D_{L}}\right)$. Only the red cell component is affected by variations in oxygen tension.

By analogy with the diffusing capacity (DL), the membrane resistance may be regarded as the reciprocal of the diffusing capacity of the alveolarcapillary membrane (DM), and the red cell resistance as the reciprocal of the capacity of the red cell to take up carbon monoxide $(\theta \mathrm{Vc})$, where $\mathrm{Vc}$ is the pulmonary capillary volume and $\theta$ is the rate of combination of carbon monoxide with blood. Values for $\theta$ have been determined by Roughton and Forster (1957), so the Vc can be calculated.

At the oxygen tension obtained breathing air the two components are of approximately equal importance in producing a resistance to gas transfer in normal subjects. The range of values for $D_{M}$ and $V c$ have been established in a preliminary study of 25 normal subjects (Hamer, 1962). A tendency for the DM to decrease with age was demonstrated. There was considerable variation in the values obtained for Vc, probably due in part to the effects of the respiratory manœuvres during measurement. 
T A B LE I

BODY SIZE AND LUNG VOLUMFS IN 30 SUBJECTS WITH PULMONARY SARCOIDOSIS

\begin{tabular}{|c|c|c|c|c|c|c|c|c|c|c|}
\hline & \multirow[t]{2}{*}{ Sex } & \multirow[t]{2}{*}{ Age } & \multicolumn{3}{|c|}{ Body Size } & \multicolumn{2}{|c|}{ Number of Tests } & \multirow{2}{*}{$\begin{array}{l}\text { Total Lung } \\
\text { Volume } \\
\text { (l.B.T.P.S.) } \\
\text { Mean of All } \\
\text { Single-breath } \\
\text { Measurements }\end{array}$} & \multirow{2}{*}{$\begin{array}{l}\text { Residual Volum } \\
\text { (l. B.T.P.S.) } \\
\text { Mean of All } \\
\text { Single-breath } \\
\text { Measurements }\end{array}$} & \multirow[b]{2}{*}{$\begin{array}{l}\text { Closed- } \\
\text { circuit } \\
\text { Method }\end{array}$} \\
\hline & & & $\begin{array}{l}\text { Height } \\
\text { (in.) }\end{array}$ & $\begin{array}{l}\text { Weight } \\
\text { (lb.) }\end{array}$ & $\underset{\left(m \cdot .^{2}\right)}{B . S . A}$ & Air & Oxygen & & & \\
\hline $\begin{array}{l}\text { P.C. } \\
\text { J.P. } \\
\text { L.S. } \\
\text { B.S. } \\
\text { C.W. } \\
\text { H.H. } \\
\text { G.S. } \\
\text { P.J. } \\
\text { J.S. } \\
\text { P.W. } \\
\text { K.C. } \\
\text { A.D. } \\
\text { E.G. } \\
\text { B.M. } \\
\text { B.O. } \\
\text { E.S. } \\
\text { H.S. } \\
\text { F.M. } \\
\text { J.D. } \\
\text { W.K. } \\
\text { T.N. } \\
\text { K.S. } \\
\text { R.B. } \\
\text { D.B. } \\
\text { V.F. } \\
\text { E.C. } \\
\text { R.M. } \\
\text { R.R. } \\
\text { G.W. } \\
\text { R.B. } \\
\text { B.O. } 2 \\
\text { C.W.2 }\end{array}$ & $\begin{array}{c}\text { M } \\
\mathbf{M} \\
\mathbf{F} \\
\mathbf{F} \\
\mathbf{M} \\
\mathbf{M} \\
\mathbf{M} \\
\mathbf{M} \\
\mathbf{M} \\
\mathbf{M} \\
\mathrm{F} \\
\mathbf{M} \\
\mathrm{F} \\
\mathbf{M} \\
\mathbf{F} \\
\mathbf{F} \\
\mathbf{F} \\
\mathbf{M} \\
\mathbf{M} \\
\mathbf{M} \\
\mathbf{F} \\
\mathbf{M} \\
\mathbf{F} \\
\mathbf{F} \\
\mathbf{F} \\
\mathbf{F} \\
\mathbf{F} \\
\mathbf{F} \\
\mathbf{M} \\
\mathbf{M} \\
\mathbf{F} \\
\mathbf{F} \\
\mathbf{M}\end{array}$ & $\begin{array}{l}27 \\
36 \\
29 \\
30 \\
28 \\
39 \\
35 \\
28 \\
37 \\
33 \\
56 \\
21 \\
54 \\
36 \\
30 \\
30 \\
23 \\
43 \\
46 \\
40 \\
51 \\
52 \\
59 \\
39 \\
35 \\
37 \\
43 \\
41 \\
33 \\
58 \\
40 \\
31 \\
28\end{array}$ & $\begin{array}{l}68 \\
71 \\
67 \\
64 \\
68 \\
70 \\
68 \\
70 \\
71 \\
69 \\
63 \\
71 \\
66 \\
67 \\
59 \\
66 \\
66 \\
65 \\
68 \\
71 \\
67 \\
63 \\
64 \\
64 \\
61 \\
60 \\
64 \\
65 \\
69 \\
63 \\
64 \\
60 \\
68\end{array}$ & $\begin{array}{l}137 \\
166 \\
112 \\
136 \\
140 \\
180 \\
172 \\
137 \\
184 \\
187 \\
130 \\
135 \\
148 \\
155 \\
106 \\
138 \\
90 \\
164 \\
153 \\
155 \\
148 \\
138 \\
164 \\
132 \\
120 \\
140 \\
135 \\
110 \\
156 \\
120 \\
148 \\
110 \\
145\end{array}$ & $\begin{array}{l}1.74 \\
1.94 \\
1.58 \\
1.66 \\
1.74 \\
2.00 \\
1.92 \\
1.77 \\
2.00 \\
2.01 \\
1.63 \\
1.77 \\
1.76 \\
1.81 \\
1.40 \\
1.70 \\
1.42 \\
1.82 \\
1.83 \\
1.89 \\
1.77 \\
1.65 \\
1.80 \\
1.64 \\
1.51 \\
1.60 \\
1.65 \\
1.52 \\
1.86 \\
1.56 \\
1.72 \\
1.45 \\
1.77\end{array}$ & $\begin{array}{l}2 \\
3 \\
4 \\
2 \\
2 \\
2 \\
2 \\
3 \\
1 \\
1 \\
1 \\
2 \\
2 \\
2 \\
2 \\
1 \\
2 \\
2 \\
3 \\
1 \\
2 \\
2 \\
2 \\
2 \\
1 \\
2 \\
2 \\
1 \\
2 \\
1 \\
2 \\
2\end{array}$ & $\begin{array}{l}2 \\
3 \\
2 \\
2 \\
2 \\
2 \\
2 \\
3 \\
1 \\
1 \\
1 \\
2 \\
2 \\
2 \\
2 \\
1 \\
2 \\
2 \\
3 \\
1 \\
2 \\
2 \\
2 \\
2 \\
2 \\
2 \\
2 \\
1 \\
2 \\
2 \\
1 \\
2 \\
2\end{array}$ & $\begin{array}{l}5 \cdot 75 \\
6 \cdot 16 \\
4 \cdot 80 \\
4 \cdot 52 \\
6 \cdot 46 \\
5 \cdot 38 \\
5 \cdot 79 \\
4 \cdot 00 \\
6 \cdot 22 \\
5 \cdot 68 \\
3 \cdot 07 \\
4 \cdot 94 \\
3 \cdot 51 \\
4 \cdot 53 \\
3 \cdot 48 \\
3 \cdot 53 \\
3 \cdot 22 \\
4 \cdot 74 \\
5 \cdot 18 \\
4 \cdot 37 \\
3 \cdot 80 \\
5 \cdot 09 \\
3 \cdot 62 \\
4 \cdot 15 \\
3 \cdot 59 \\
3 \cdot 60 \\
3 \cdot 04 \\
3 \cdot 58 \\
4 \cdot 56 \\
3 \cdot 40 \\
4 \cdot 00 \\
3 \cdot 58 \\
6 \cdot 62\end{array}$ & $\begin{array}{l}1.93 \\
1.68 \\
1.79 \\
1.90 \\
1.32 \\
1.25 \\
1.48 \\
1.65 \\
1.90 \\
1.43 \\
1.26 \\
1.78 \\
1.79 \\
1.37 \\
1.53 \\
1.19 \\
1.35 \\
1.25 \\
2.29 \\
1.39 \\
1.35 \\
1.80 \\
1.09 \\
1.76 \\
1.24 \\
0.90 \\
1.05 \\
1.29 \\
1.41 \\
1.51 \\
1.53 \\
1.26 \\
1.54\end{array}$ & $\begin{array}{l}1.46 \\
1.11 \\
1.62 \\
0.61 \\
1.28 \\
1.47\end{array}$ \\
\hline
\end{tabular}

\section{METHODS}

Thirty patients with pulmonary infiltration due to sarcoidosis were studied. Details of age, sex, and body size are given in Table I. These subjects had been under observation in a special clinic for varying periods up to 16 years with regular radiological examination, and their clinical course was well documented. In seven cases pulmonary infiltration appeared while the patients were under observation, so the duration of the lung changes was accurately known. The remaining patients had pulmonary parenchymal changes on their chest radiograph when first seen. The diagnosis was confirmed histologically by lymph node, conjunctival or hepatic biopsy in 20 patients.

An attempt was made to study patients at all stages of the disease, so the cases cannot be regarded as representative of the relative incidence of various types of pulmonary sarcoidosis. An analysis of the symptoms and physical signs was not considered worth while in this study, as changes were usually minor except in the few severely affected patients. The radiographs were reviewed without knowledge of the results of the diffusion measurements, and the current film was classified as normal or as showing pulmonary infiltration, with or without pulmonary fibrosis (Figs. 2 and 3). The criteria for pulmonary fibrosis were those proposed by Smellie and Hoyle (1960), i.e., linear streaking and local condensation, especially around elevated hilar shadows, tending to $\stackrel{\mathbb{}}{\varrho}$ spread horizontally into the lower parts of the upper $\overrightarrow{\overrightarrow{0}}$ zones of both lungs. It is recognized that diffuse 3 fibrosis may be present histologically without these $\bar{T}$ findings which indicate more coarse localized changes. In view of the changes in radiographic appearance that can be produced by differences in technique, no estimate of the severity of infiltration or fibrosis was $\frac{0}{\mathrm{~g}}$ thought justified. The known duration of each type $\times$ of radiographic appearance was noted.

Eight patients were receiving steroid therapy at the time of study, and six others had received treatmento of this type in the past. In addition three subjects were studied before and during steroid treatment.을 Seven patients were cigarette smokers and two (P. J. and V.S.) were thought to have chronic bronchitis in addition to pulmonary sarcoidosis. One patient (P. C.) had had Myco. tuberculosis in the sputum and hadN received suitable chemotherapy several years previously. In another patient (J.S.) a spontaneous 0 pneumothorax had required pleurodesis in the past. N

In most subjects the studies were performed fromo the out-patient department without special preparation Diffusing capacity for carbon monoxide was measured at two oxygen tensions, using the technique described by Ogilvie, Forster, Blakemore, and Morton (1957): with some modifications. After a full but unforced expiration a maximal breath of gas containing ${ }_{\mathbb{D}}$ approximately $0.2 \%$ carbon monoxide and $15 \% \mathcal{Q}$ helium was held for about 10 seconds. Two gas $\mathbb{Q}$ 


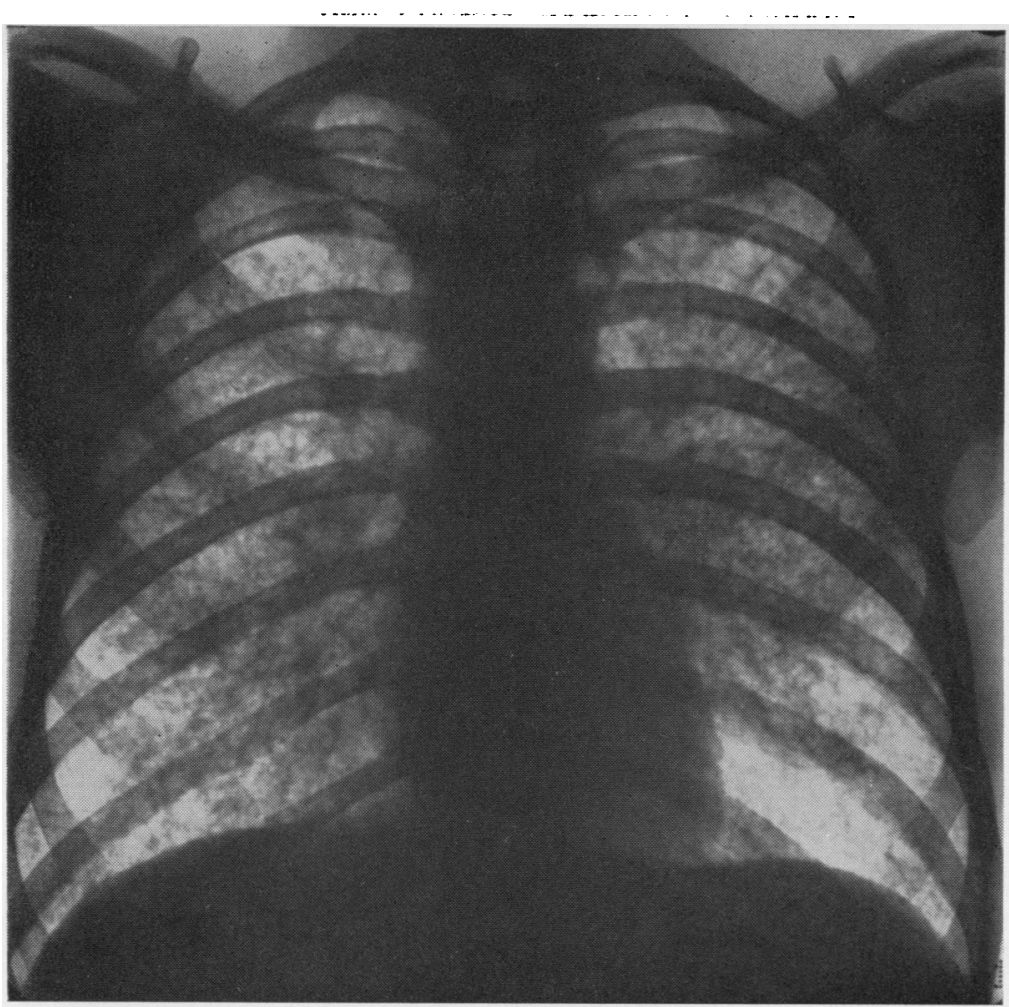

I IG. 2

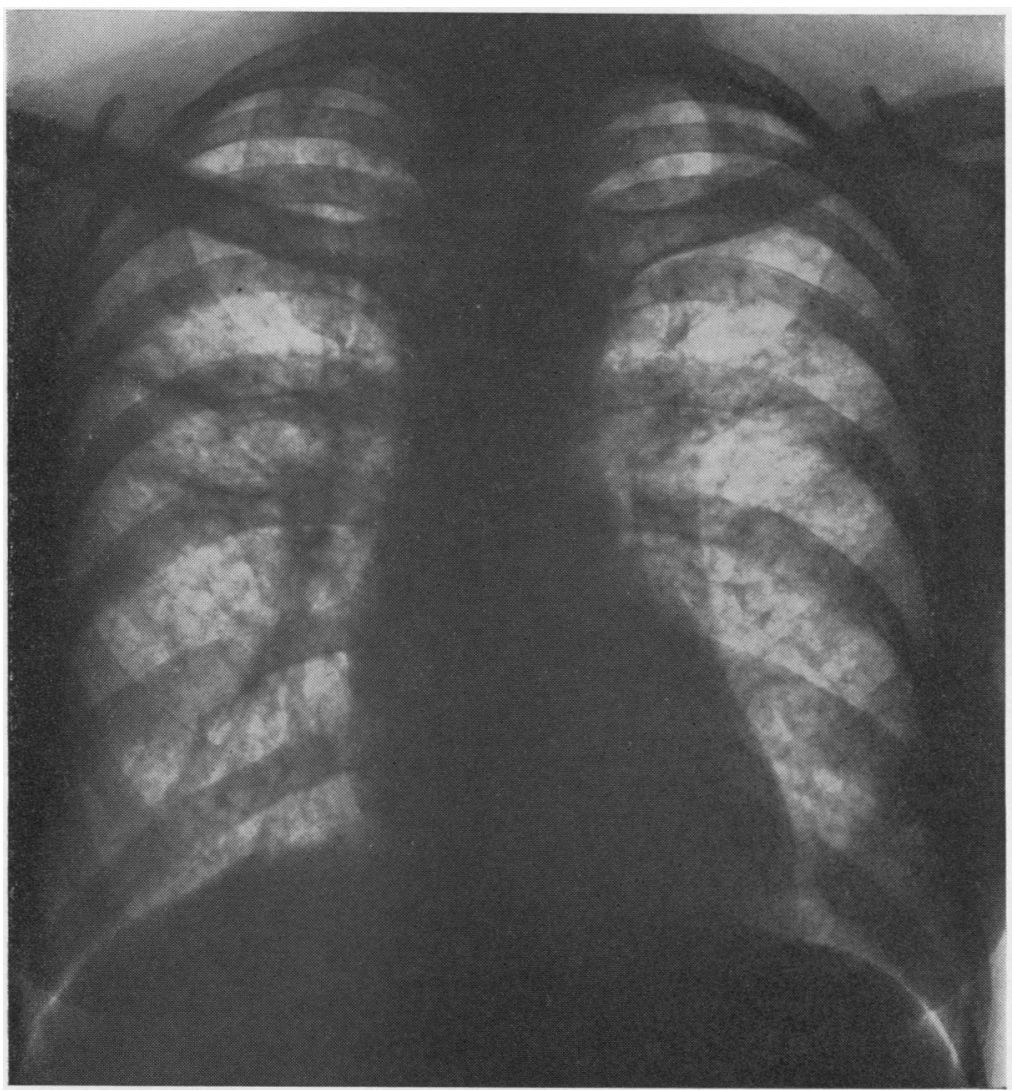

FIG. 3

FIGS. 2 and 3. Typical radiological appearances of pulmonary infiltration in sarcoidosis. Fig. 2 (A.D.) shows uncomplicated infiltration, but in Fig. 3 (R.M.) there are also changes due to pulmonary fibrosis. 
mixtures were used, one containing only oxygen in addition to the carbon monoxide and helium (referred to as the 'oxygen' mixture) and the other $20 \%$ oxygen with the remainder nitrogen (referred to as the 'air' mixture). A single three-way tap was used to reduce the dead space of the apparatus. Rubber bags were applied to the outlet of the tap using tapered air-tight connectors and were then evacuated by a suction line. A sample was collected after the expiration of about 1 litre to flush out the dead space. Sampling time was kept as short as possible, and in general approximately 1 litre of expirate was collected in about half a second.

Part of each sample was transferred to a mercury tonometer for the subsequent measurement of the oxygen and carbon dioxide contents by the Scholander method. The remainder of the sample was then drawn through a carbon dioxide absorber to the gas analysers at approximately 0.5 litre/minute. The gas to be inspired was drawn through a humidifier to the analysers before each estimation. Approximately 0.5 litre of gas was needed for accurate measurement of carbon monoxide and helium. The gas passed first to a Cambridge catharometer set to read helium concentrations in moist air. The catharometer readings were corrected for variations in oxygen content on the basis of a reading of $1.9 \%$ helium with $100 \%$ oxygen, assuming a linear increase in the reading between $21 \%$ and $100 \%$ oxygen in the gas carrying the helium. After passing through a water absorber (magnesium perchlorate) the gas passed through a carbon monoxide analyser ${ }^{1}$ (type SCLA). This instrument was calibrated before each study with a standard gas mixture supplied by the makers. One scale, extending from 0.03 to 0.25 carbon monoxide, was used for measurement of both the inspired and expired gas, and the linearity of the response was confirmed by comparison with the catharometer readings, using serial dilutions of mixtures of carbon monoxide and helium. All measurements were made as soon as the instruments had reached a steady reading after flow had stopped. The carbon monoxide and helium contents of the expired sample were corrected for the carbon dioxide absorbed.

The duration of breath holding and the volume of gas inspired were obtained from the spirometer chart. Breath holding was measured from the beginning of inspiration to the beginning of sample collection, and the value corrected as suggested by Jones and Meade (1961), i.e., half the sampling time was added and three-tenths of the inspiratory time subtracted, to allow for variations in the timing of inspiration and expiration. The lung volume during breath holding was calculated from the dilution of the inspired helium as suggested by McGrath and Thomson (1959), after subtraction of an estimated value for the dead space. The measurements thus correspond to those denoted $\mathrm{VA}^{\prime}$ and $\mathrm{DL}^{\prime}$ by McGrath and Thomson. In normal subjects the residual volume calculated in this way differs little from that obtained by the closed-

1 Infra Red Development Co. circuit method (McGrath and Thomson, 1959 Hamer, 1962), and errors due to variations in the extent of the preliminary expiration are reduced as $\bar{c}$ separate residual volume is calculated each time. In 11 subjects the residual volume was also measureof by the closed-circuit method for comparison.

From one to four measurements of diffusing capacity were made at each oxygen tension (Table Ifand II A). The measurements using the oxygen mix $\vec{\omega}$ ture were performed first to minimize the correction? necessary from the progressive increase in circulating carboxyhaemoglobin. The pulmonary capillary carbonmonoxide concentration was estimated by equilibra $\infty$ tion before and after each study, either by rebreathing in a six-litre closed circuit with a carbon dioxide absorber after four minutes' preliminary washout with $100 \%$ oxygen (Siösteen and Sjöstrand, 1951), or from an expired alveolar sample after a maximal breath had been held for two minutes following hyperventid lation with $100 \%$ oxygen (Forster, Roughton, Cander Briscoe, and Kreuzer, 1957). Values for each experi $\frac{\mathbb{D}}{3}$ ment were obtained by interpolation and corrected to the appropriate oxygen tension by direct proportion. The estimated pulmonary capillary carbon monoxide concentration was subtracted from both the initial an\& final alveolar carbon monoxide concentrations before calculation of the diffusing capacity. A small furthe correction was made to the initial concentration fos the carbon monoxide in the residual volumes befor each experiment.

The rate of uptake of carbon monoxide by th blood $(\theta)$ was calculated for each experiment from the relation $\frac{1}{\theta}=0.33+0.0057 \mathrm{Po} .2$, where $\mathrm{Po} .2$ is the oxygen tension in the pulmonary capillary red cel obtained from Fig. 1 of Roughton and Forster (1957) for $\lambda=\infty$, i.e., on the assumption that there is nof additional increase in the resistance to gas transfer af the red cell surface. Recent work shows no evidence of such a resistance in vivo (Thews and Niesel, 1959 $\frac{\sigma}{2}$ Yahr and Kreuzer, 1960). In five subjects examinet. while in hospital for review, $\theta$ was corrected fog variations in the systemic venous haematocrit. The values ranged from 10.6 to $14.2 \mathrm{~g}$. $\mathrm{Hb}$ per $100 \mathrm{mb}$ The appropriate oxygen tension for the calculation of $\theta$ was obtained as suggested by McNeill, Rankin, an Forster (1958) by adding $5 \mathrm{~mm}$. $\mathrm{Hg}$ to the oxyge tension of the expired sample to give an estimate of the mean alveolar oxygen tension, and subtracting the alveolar-capillary oxygen difference estimated as the oxygen consumption divided by the diffusing capacity. Oxygen uptake was taken from tableso assuming a metabolic rate $20 \%$ above basal, and the diffusing capacity for oxygen was assumed to be 1.2 帛 times that for carbon monoxide (Krogh, 1915). Thळ physical process of diffusion, from which this ratio is derived, is only one of the factors contributing to the diffusing capacity of the lung, but the erro produced by this assumption is relatively small.

Pairs of measurements of the diffusing capacit $\overrightarrow{\$}$ (DL) and the rate of uptake of carbon monoxide b 
TABLE II

RESULTS OF SINGLE-BREATH MEASUREMENTS IN 30 SUBJECTS WITH PULMONARY SARCOIDOSIS

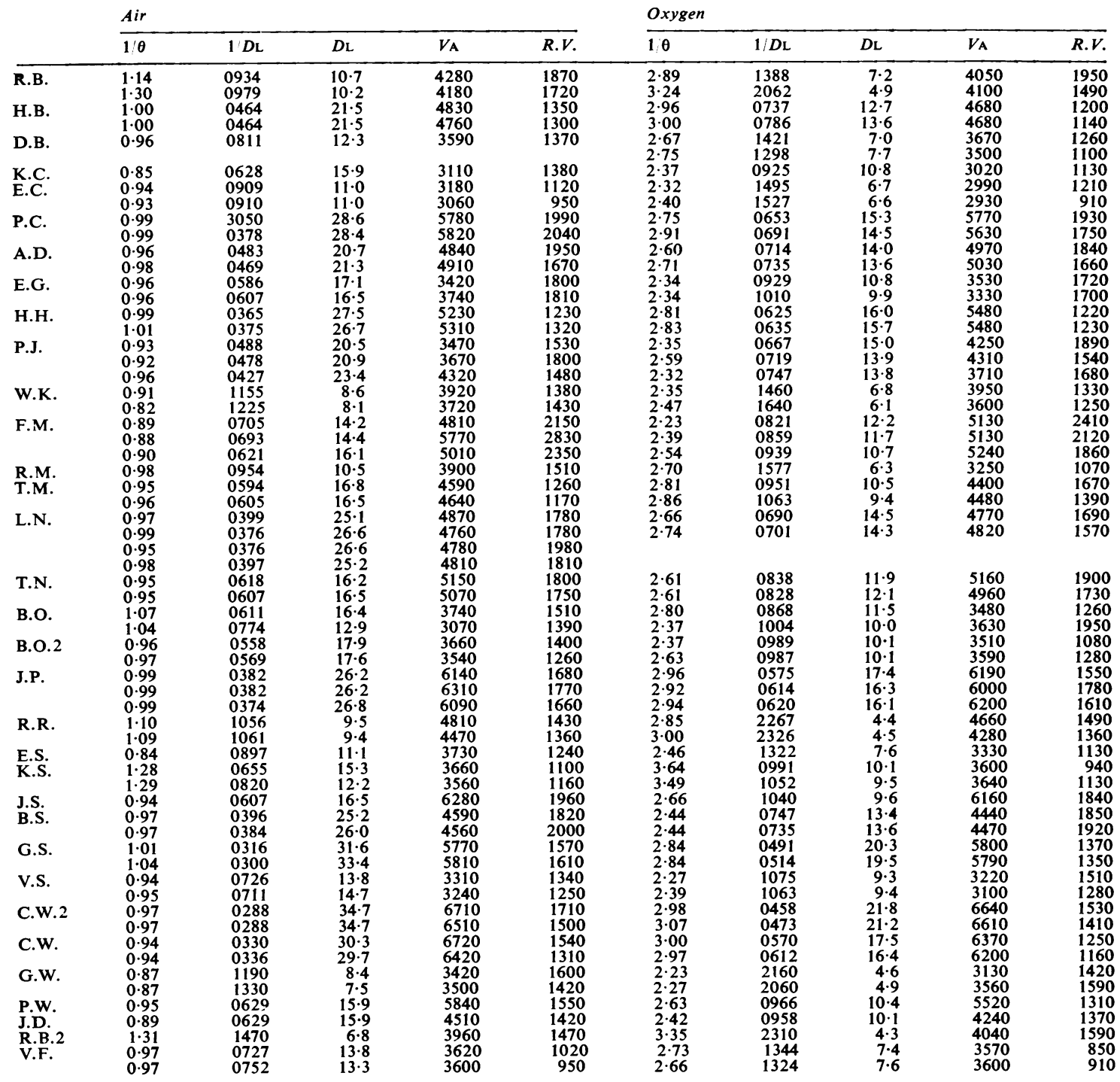

TABLE II A

RESULTS OF SINGLE-BREATH MEASUREMENTS IN THREE SUBJECTS WITH PULMONARY SARCOIDOSIS

Mean values in the three groups defined on the basis of the values

\begin{tabular}{|c|c|c|c|c|c|}
\hline \multirow{2}{*}{$\begin{array}{l}\text { DM and Vc } \\
\text { Results }\end{array}$} & \multirow{2}{*}{$\begin{array}{l}\text { No. of } \\
\text { Sub- } \\
\text { jects }\end{array}$} & \multicolumn{2}{|c|}{ Air Mixture } & \multicolumn{2}{|c|}{ Oxygen Mixture } \\
\hline & & $1 / \theta$ & $D \mathrm{~L}$ & $1 / \theta$ & $D_{\mathbf{L}}$ \\
\hline $\begin{array}{l}\text { Nor } \\
\text { Red } \\
\text { Red }\end{array}$ & $\begin{array}{r}7 \\
16 \\
7\end{array}$ & $\begin{array}{l}0.98 \\
0.96 \\
1.03\end{array}$ & $\begin{array}{l}28 \cdot 4 \\
16 \cdot 3 \\
10 \cdot 3\end{array}$ & $\begin{array}{l}2 \cdot 83 \\
2.60 \\
2 \cdot 71\end{array}$ & $\begin{array}{r}17.5 \\
10.9 \\
6.0\end{array}$ \\
\hline
\end{tabular}

$\mathrm{DL}$ in $\mathrm{ml} . / \mathrm{mm}$. $\mathrm{Hg} / \mathrm{min}$.; $\theta$ in $\mathrm{ml} . / \mathrm{ml} . / \mathrm{mm}$. $\mathrm{Hg} / \mathrm{min}$. the blood $(\theta)$ at different oxygen tensions were used to obtain the membrane component (DM) and the capillary volume $(\mathrm{Vc})$ from the equation $1 / \mathrm{DL}=$ $1 / \theta \mathrm{Vc}+1 / \mathrm{DM}$. A standard value of DL was found in each case by putting $\theta=1$; this corresponds to a red cell oxygen tension of about $120 \mathrm{~mm}$. Hg.

The graphical solution of the equation is shown in Fig. 4 in which $\frac{1}{\mathrm{DL}_{\mathrm{L}}}$ is plotted against $\frac{1}{\theta}$, which varies linearly with oxygen tension. The values expected at the two levels of oxygen tension in a normal subject are shown. The oblique line between these points 


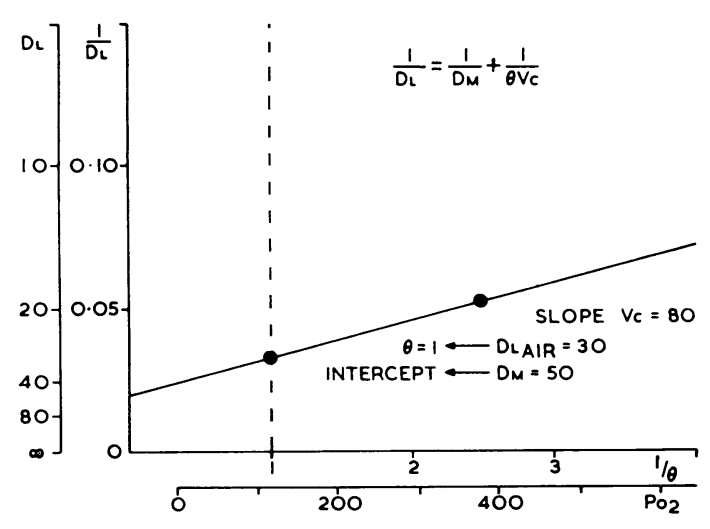

FIG. 4. Calculation of $D \mathrm{M}$ and $V c$ in a normal subject.

shows the effect of variations in oxygen tension on the diffusing capacity for carbon monoxide. The slope of the line gives the $\mathrm{Vc}$, a steeper slope indicating a smaller volume, and the intercept, at $\frac{1}{\theta}=0$, gives the DM, which is unaffected by variations in oxygen tension. The diffusing capacities (DL and DM) are expressed throughout in $\mathrm{ml} . / \mathrm{mm}$. $\mathrm{Hg} / \mathrm{min}$. and capillary volume $(\mathrm{Vc})$ in millilitres. The DL, DM, and Vc were regarded as abnormal if more than three standard errors from the regression equation for age in normal subjects (Table III), using the less skew

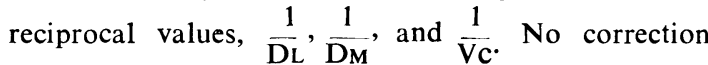
was attempted for variation in body size.

\section{T A B LE I I I}

NORMAL VALUES IN 25 SUBJECTS (HAMER, 1962) EXPRESSED AS REGRESSION EQUATION FOR AGE

\begin{tabular}{lccc}
$y$ & $c$ & $100 \mathrm{~m}$ & $S . E$. \\
\hline$\frac{1}{\mathrm{DL}}$ & 0.0250 & 0.0282 & 0.0056 \\
$\frac{1}{\mathrm{DM}}$ & 0.0122 & 0.0221 & 0.0033 \\
$\frac{1}{\mathrm{Vc}}$ & 0.0129 & 0.0060 & 0.0045 \\
$\mathrm{y}=\mathrm{mx}+\mathrm{c} ; \mathrm{x}=$ age in completed years &
\end{tabular}

Lung volumes were expressed as percentages of the values predicted from the regression equations for residual volume and vital capacity given in Table $X$ of Needham, Rogan, and McDonald (1954), adding $6 \%$ to bring the values to B.T.P.S.

\section{RESULTS}

The total lung volume estimated from the dilution of helium during the breath-holding manœuvre was on the average $77 \%$ (53 to $93 \%$ ), and the corresponding residual volume $79 \%$ (56 to $122 \%$ ) of the value predicted (Table IV). There was no evident correlation between the lung volumes and $\bar{C}$ the severity of the changes judged on other grounds. In 11 patients residual volume was also measured by helium dilution in a closed circuit $\stackrel{\odot}{\complement}$ for 7 minutes; the results were similar to those obtained during breath holding (Table I), but the closed-circuit measurements tended to be smaller, the average difference being $92 \mathrm{ml} . \quad(1,322 \vec{\omega}$ compared to $1,414 \mathrm{ml}$.).

The results of the diffusion studies (Table IV) fell into three groups; seven subjects showed $\vec{\infty}$ normal values, 16 had impairment of DM with $a_{\omega}^{\infty}$ normal Vc, and in seven cases both componentsin (DM and Vc) were reduced. The mean values inct each group are shown in Table V. In Fig. 5 these응 average findings are shown graphically, $1 / D_{L}-$

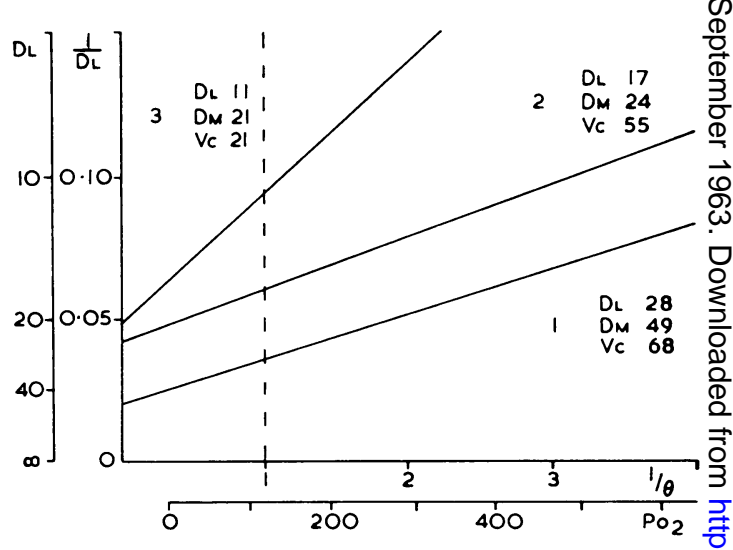

FIG. 5. Average findings in the three groups of patients with sarcoidosis. $D \mathrm{M}$ is given by the intercept at $\frac{1}{\theta}=0, D_{\mathrm{L}} \stackrel{\overrightarrow{0}}{\frac{\mathrm{O}}{\alpha}}$ by the value at $\frac{1}{\theta}=1$, and $V c$ by the slope of the line in each group.

being plotted against $1 / \theta$ as in Fig. 4. The first group shows a normal slope and intercept, the second group shows elevation of the intercept $>$ without any change in the slope of the line, and? the third group shows a similar intercept but then line slopes more steeply as Vc is reduced.

Several types of radiographic change were found $\tilde{o}$ in each of the groups defined on the basis of the diffusion studies (Table VI). In five patients radiographic changes had been present for severalo years but had resolved a few years before the investigation. Two of these patients had normal $\stackrel{?}{+}$ diffusion, and the other three had impairment of 0 DM only.

Pulmonary infiltration was present at the time

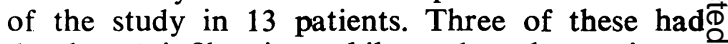
developed infiltration while under observation ao 
TA B LE IV

RESULTS OF DIFFUSION AND LUNG VOLUME MEASUREMENTS WITH DETAILS OF RADIOGRAPHIC CHANGES AND STEROID THERAPY IN 30 PATIENTS WITH PULMONARY SARCOIDOSIS

Initials

$$
\frac{\text { Diffusion Measurements }}{D \mathrm{~L}} V_{\mathrm{M}} \quad \frac{\begin{array}{l}
\text { Lung Volumes } \\
(\text { as \% predicted })
\end{array}}{\text { Total Residual }}
$$

Duration of Radiographic Changes

(years)

Duration of Steroid Therapy

Infiltration Subsequent Additional Current Previous Ceased Clearing Fibrosis

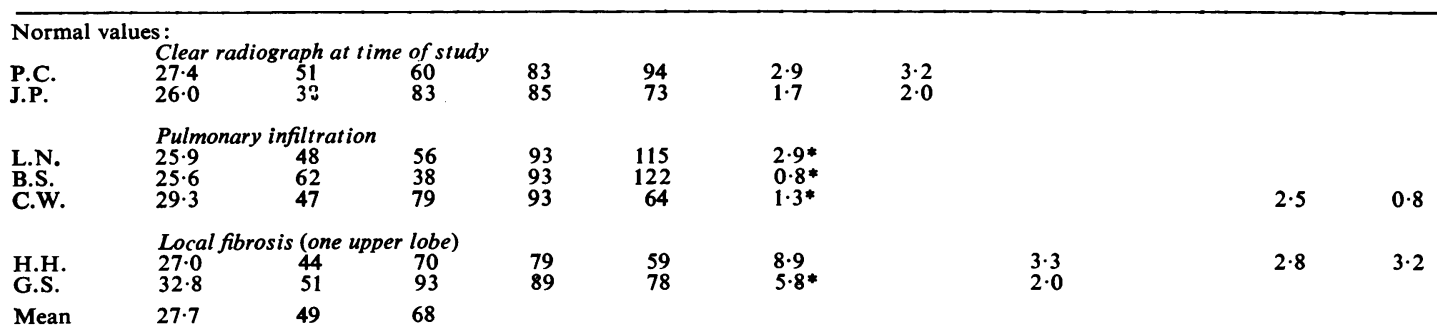

Impaired DM only:

\begin{tabular}{llc} 
Impaired DM only: & Clear & radiograph at time \\
P.J. & $21 \cdot 1$ & 33 \\
J.S. & 16.5 & 26 \\
P.W. & 15.9 & 23 \\
& \multicolumn{3}{c}{ Pulmonary } & infiltration \\
K.C. & $21 \cdot 6$ & 15 \\
A.D. & 20.8 & 30 \\
E.G. & 16.5 & 30 \\
T.M. & 15.3 & 25 \\
B.O. & 14.6 & 19 \\
E.S. & 19.8 & 36 \\
V.S. & 13.7 & 21
\end{tabular}

of study

$\begin{array}{ll}60 & 53 \\ 41 & 89 \\ 50 & 86\end{array}$

$\begin{array}{llll}53 & 72 & 0.9 & 4 \cdot 6 \\ 89 & 90 & 2 \cdot 9 * & 1.5 \\ 86 & 81 & 1 \cdot 8 & 9 \cdot 1\end{array}$

$1 \cdot 6$

$\begin{array}{ll}51 & 69 \\ 68 & 64 \\ 37 & 73 \\ 38 & 70 \\ 63 & 81 \\ 49 & 80 \\ 39 & 63\end{array}$

70
80
100
70
98
60
90

$5 \cdot 8$
$1 \cdot 5 *$
$4 \cdot 5$
$3 \cdot 3$
$2 \cdot 8$
$3 \cdot 2$
$9 \cdot 0$

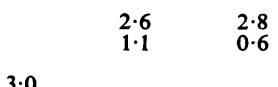

$\begin{array}{lll} & \text { Local fibrosis (one upper lobe) } \\ \text { H.B. } & 21.5 & 68\end{array}$

H.B.

Generalized fibrosis

W.D.

W.K.

$\begin{array}{lcl}\text { Generalized fibrosis } & \\ 15 \cdot 3 & 23 & 47 \\ 8 \cdot 4 & 10 & 43 \\ 16 \cdot 3 & 20 & 75 \\ 14 \cdot 2 & 17 & 80 \\ 16 \cdot 6 & 24 & 55\end{array}$

77
79

$\begin{array}{ll}57 & 13.4\end{array}$

$15 \cdot 4$

$4 \cdot 4$
$3 \cdot 3$

$0.5 \quad 2.9$

0.8

Mean

$16 \cdot 6$

$\begin{array}{ll}47 & 60 \\ 43 & 77 \\ 75 & 92 \\ 80 & 80\end{array}$

$\begin{array}{ll}56 & 6 \cdot 6 \\ 77 & 8 \cdot 6 \\ 84 & 6 \cdot 3\end{array}$

$6 \cdot 6$
$8 \cdot 6$
$6 \cdot 3$
$8 \cdot 5$

$3 \cdot 1$
$5 \cdot 5$
$4 \cdot 1$
$5 \cdot 5$

$\begin{array}{lll}8.6 & 2.9 & 0.3\end{array}$

Impaired DM and Vc:

R.B. Pulmonary infiltration

R.B. $\quad 11.6$

$\begin{array}{ll}22 & 25 \\ 20 & 12 \\ 25 & 29\end{array}$

25
12
29

$\begin{array}{rrr}87 & 107 & 14 \cdot 0 \\ 80 & 78 & 8 \cdot 2 * \\ 83 & 56 & 5 \cdot 0\end{array}$

$\begin{array}{rrr} & 0 \cdot 3 & 7 \cdot 3 \\ 1 \cdot 2 & 2 \cdot 0 & 3 \cdot 0\end{array}$

Generalized fibrosis

E.C.

R.R.

G.W.

$10 \cdot 7 \quad 20$

Mean

$10 \cdot 5$

$10 \cdot 1$
$7 \cdot 5$

20
17
31
14

24
28
15
16

65
74
66

$\begin{array}{lr}62 & 7 \cdot 3 \\ 78 & 7 \cdot 6 \\ 67 & 8 \cdot 8 \\ 61 & 12 \cdot 4\end{array}$

$1 \cdot 8$
$4 \cdot 6$
$3 \cdot 5$
$4 \cdot 4$

$3 \cdot 3$
$4 \cdot 8$

Second studies after steroid therapy:

\begin{tabular}{lccrcc}
\multicolumn{2}{c}{ Second studies after steroid therapy: } & & & \\
R.B. & 7.5 & 11 & 24 & 84 & 93 \\
B.O. & 17.5 & 31 & 41 & 81 & 80 \\
C.W & 34.5 & 49 & 116 & 96 & 78
\end{tabular}

C.W. $\quad 34.5$

* Onset under observation

TABLE V

MEAN VALUES OF DL, DM, AND Vc IN EACH GROUP

\begin{tabular}{|c|c|c|c|c|}
\hline & Number & $D \mathrm{~L}$ & $D_{M}$ & $V c$ \\
\hline \multirow{4}{*}{$\begin{array}{l}\text { Normal series } \\
\text { (Hamer, 1962) } \\
\text { Sarcoid: : } \\
\text { narmal values } \\
\text { Sarcoid: } \\
\text { low DM Donly } \\
\text { Sarcoid: } \\
\text { low DM and Vc }\end{array}$} & 25 & $29 \cdot 4$ & 52 & 75 \\
\hline & 7 & $27 \cdot 7$ & 49 & 68 \\
\hline & 16 & $16 \cdot 6$ & 24 & 55 \\
\hline & 7 & 10.8 & 21 & 21 \\
\hline
\end{tabular}

TABLE VI

RELATION BETWEEN RADIOGRAPHIC AND DIFFUSION CHANGES IN 30 PATIENTS WITH PULMONARY SARCOIDOSIS

\begin{tabular}{|c|c|c|c|}
\hline & Normal & $\begin{array}{l}\text { Low DM } \\
\text { Only }\end{array}$ & $\begin{array}{l}\text { Low } D_{\mathrm{M}} \\
\text { and } V c\end{array}$ \\
\hline $\begin{array}{l}\text { Clear radiographs } \\
\text { Infiltration } \\
\text { Local fibrosis } \\
\text { Bilateral fibrosis }\end{array}$ & $\begin{array}{l}2 \\
3 \\
2\end{array}$ & $\begin{array}{l}3 \\
7 \\
2 \\
4\end{array}$ & $\begin{array}{l}3 \\
4\end{array}$ \\
\hline
\end{tabular}




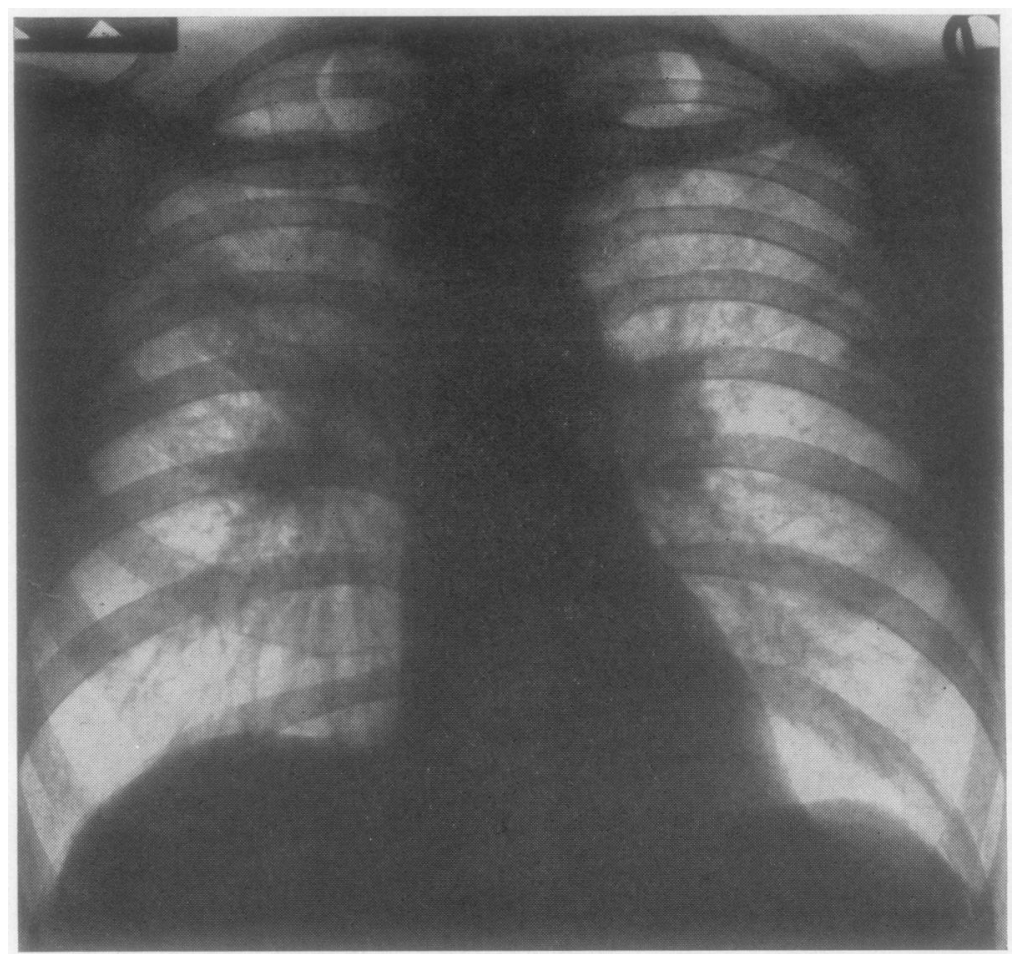

FIG. 6

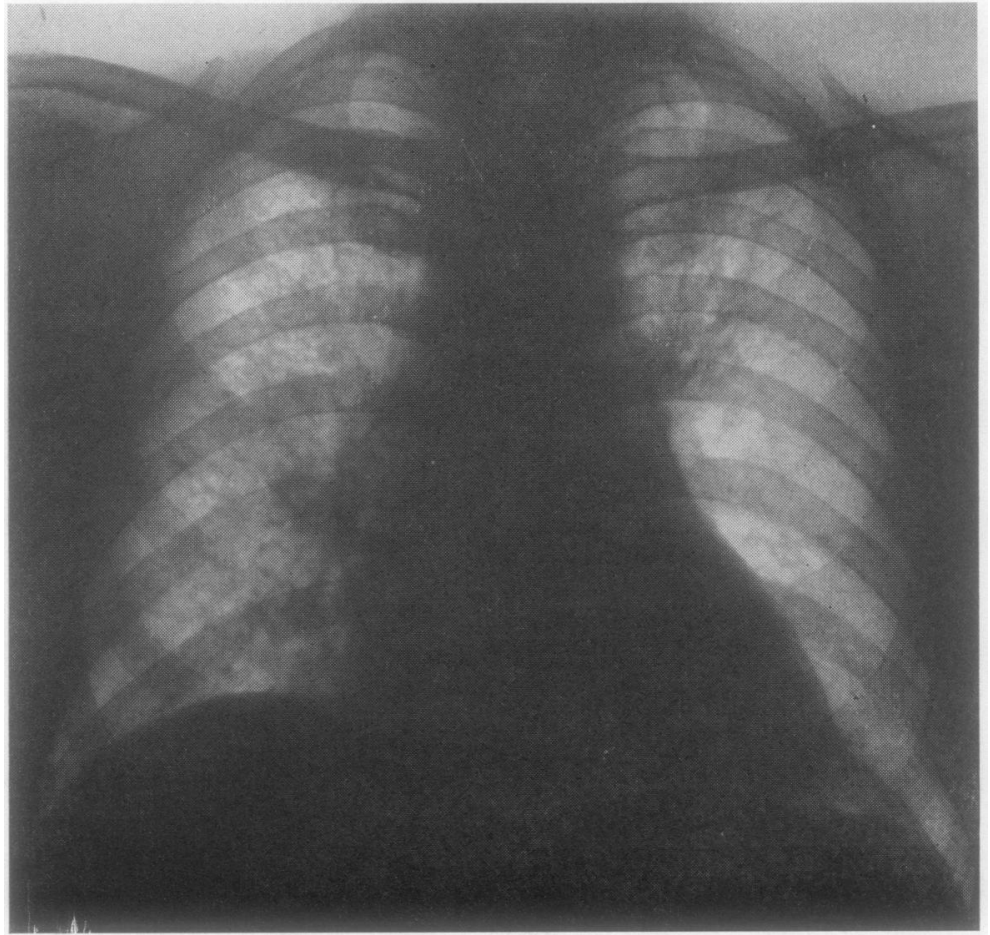

FIG. 7

FIGS. 6 and 7. Radiological appearances in two patients with fibrosis affecting one upper lobe. In Fig. 6 (G.S.) the remainder of the lung fields are normal, but in Fig. 7 (H.B.) there is some persistent infiltration. 
short time previously and had normal diffusion. Seven with moderately long-standing infiltration had reduction in DM only, and three with a long history of infiltration had low values for both components (DM and $\mathrm{Vc}$ ).

Local fibrosis affecting one upper lobe was found in four patients with long-standing radiological changes. There was complete clearing elsewhere in two subjects who showed normal diffusion (Fig. 6), but some infiltration persisted in the other two who had impairment of DM only (Fig. 7). Bilateral fibrosis was evident in the radiograph in eight cases, all with a long history. Four of these patients had a reduced DM only and four had low values for both components (DM and Vc).

In the patients with pulmonary infiltration but no fibrosis there is a trend to more severe changes in diffusion the longer the history of radiological changes in the lungs. When the diffusing capacity of the alveolar-capillary membrane for the whole group is compared with the known duration of radiographic changes (Fig. 8) there is a tendency

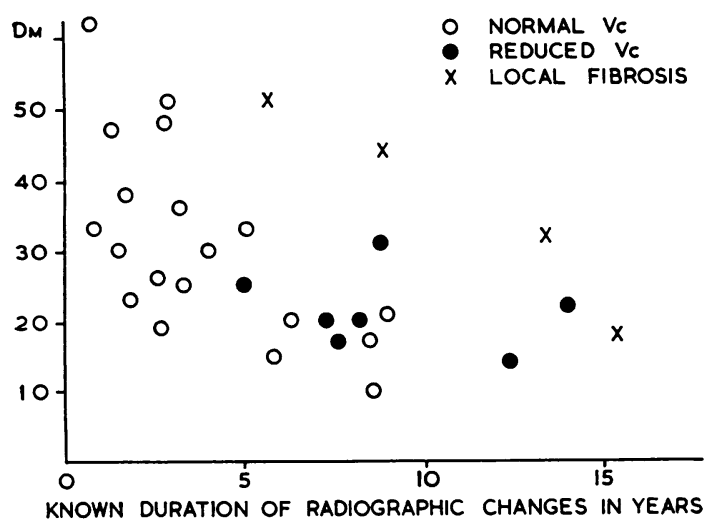

FIG. 8. Relation between DM and the known duration of radiographic changes.

for a rapid fall in the first few years and a more gradual reduction in more long-standing disease. ${ }^{1}$ The patients with local fibrosis show less impairment in the membrane component than expected from the duration of the disease. Reduction in capillary volume is confined to patients with known radiographic changes for more than five years, and nearly half the patients with disease of this duration are affected in this way.

The effects of steroid therapy were studied in three patients with pulmonary infiltration but no

1 The correlation between DM and the known duration of radiographic changes is statistically significant $(r=0.47, t=3.4, P<0.01)$. $\mathbf{X}$
TABLE VII

EFFECT OF STEROID THERAPY IN THREE PATIENTS WITH PULMONARY SARCOIDOSIS

\begin{tabular}{|c|c|c|c|c|c|c|}
\hline \multirow{2}{*}{$\begin{array}{l}\text { Duration of } \\
\text { Radiographi } \\
\text { Changes } \\
\text { before } \\
\text { Therapy } \\
\text { (years) }\end{array}$} & \multicolumn{4}{|c|}{$\begin{array}{l}\text { Duration Diffusion Changes } \\
\text { c of }(\%)\end{array}$} & \multicolumn{2}{|c|}{$\begin{array}{l}\text { Lung Volume } \\
\text { Changes } \\
(\%)\end{array}$} \\
\hline & $\begin{array}{l}\text { Srerola } \\
\text { Therapy } \\
\text { (years) }\end{array}$ & $\overline{D L}$ & $D_{M}$ & $\overline{V c}$ & $\frac{(\%)}{\text { T.L.C. }}$ & $\overline{R . V .}$ \\
\hline $\begin{array}{r}14 \cdot 0 \\
2 \cdot 8 \\
1 \cdot 3 \\
6 \cdot 0\end{array}$ & $\begin{array}{l}1.5 \\
1.0 \\
0.1 \\
0.9\end{array}$ & $\begin{array}{r}-35 \\
+20 \\
+18 \\
+1\end{array}$ & $\begin{array}{r}-50 \\
+63 \\
+4 \\
+6\end{array}$ & $\begin{array}{r}-4 \\
-35 \\
+47 \\
+3\end{array}$ & $\begin{array}{l}-4 \\
+3 \\
+3 \\
+1\end{array}$ & $\begin{array}{r}-13 \\
-18 \\
+17 \\
-5\end{array}$ \\
\hline
\end{tabular}

radiological evidence of fibrosis. Each type of diffusion abnormality was represented (Table VII). There was no definite change in radiological or diffusion findings as a result of steroid therapy in these three patients. One patient showed deterioration in DM despite steroid therapy, whereas the other two improved in some parameters. The mean changes were negligible.

\section{DISCUSSION}

FUNCTIONAL CHANGES IN THE LUNGS The classification of the functional abnormalities in pulmonary sarcoidosis as ventilatory restriction, sometimes complicated by a diffusion defect, or as predominantly ventilatory obstruction (McClement, Renzetti, Himmelstein, and Cournand, 1953) has been largely confirmed by subsequent studies (Stone, Schwartz, Feltman, and Lovelock, 1953 ; Marshall et al., 1958 ; Svanborg, 1961). Early work indicated that restrictive changes, with reduced lung volumes and a tendency to hyperventilation but no evidence of airway obstruction, were common in pulmonary sarcoidosis (Bruce and Wassén, 1940 ; Leitner, 1946 ; Baldwin, Cournand, and Richards, 1949 ; Small, 1951 ; Shulman, Schoenrich, and Harvey, 1952 ; Williams, 1953 ; Gray and Gray, 1957 ; Morrison, Fulton, and Hickam, 1957), and this has been confirmed in more recent studies. The corresponding changes in the mechanical properties of the lung are usually small (Marshall and DuBois, 1956 ; Marshall et al., 1958 ; Svanborg, 1961).

The frequency with which abnormalities of diffusion have been recognized in these patients has varied with the techniques available. Riley, Riley, and Hill (1952) reported three cases of pulmonary sarcoidosis with impaired diffusion for oxygen, and similar cases were reported by Williams (1953) and by Austrian, McClement, Renzetti, Donald, Riley, and Cournand (1951). Five of the nine patients with restrictive changes reported by McClement and his colleagues (1953) showed impairment of oxygen diffusion. Stone 
et al. (1953) found similar evidence of reduced diffusion in five of 12 such patients.

The introduction of the more convenient carbon monoxide method for the measurement of diffusion led to more frequent reports of diffusion changes in sarcoidosis (Bates, 1958). Marshall et al. (1958), in their study of 21 patients with pulmonary sarcoidosis, found that a reduction of diffusing capacity was the principal disturbance. Low values were found in 13 of these subjects. Svanborg (1961) studied 26 patients and found impaired diffusion in 19.

Obstructive changes, with an increase in residual volume and an abnormal distribution of ventilation, were reported by Coates and Comroe (1951). Later studies have shown this type of abnormality in a minority of cases (McClement et al., 1953; Stone et al., 1953 ; Marshall et al., 1958 ; Svanborg, 1961), usually without any increase in residual volume. These ventilatory abnormalities are thought to indicate bronchial constriction without alveolar destruction or bronchiolar collapse, as there is little evidence of functional changes of the type found in chronic obstructive emphysema. In the present study lung volumes were in general somewhat less than predicted, and there was no evidence of a pathological increase in residual volume in any case. The detailed studies of Marshall and his colleagues (1958) and of Svanborg (1961) suggest that restrictive changes are relatively mild and obstructive changes uncommon in pulmonary sarcoidosis, and that impairment of diffusion is the predominant abnormality.

There has been little previous work on the components of the diffusing capacity in patients with pulmonary sarcoidosis. McNeill et al. (1958) studied two patients with diffuse pulmonary fibrosis due to sarcoidosis and found the membrane component (DM) to be reduced to a greater extent than the capillary volume $(\mathrm{Vc})$. Johnson, Lawson, and Wilcox (1961) report in summary the findings in nine patients with pulmonary sarcoidosis. Reduction of DM was the major change, the Vc being relatively little affected, even in two cases of 'cor pulmonale'. The changes reported in these studies are similar to those found in the present work.

Bates, Varvis, Donevan, and Christie (1960) studied the components of the diffusing capacity in two patients with pulmonary sarcoidosis, using a steady-state method on exercise instead of the single-breath technique. The main change found was a low Vc with a normal DM in one subject. This pattern of impairment was not encountered in the present study.
CORRELATION OF RADIOLOGICAL APPEARANCES WITH CHANGES IN DIFFUSING CAPACITY The absence of $\frac{}{\bar{n}}$ any correspondence between the changes in $\frac{\bar{\sigma}}{\sigma}$ diffusion and the radiological status at the time $\stackrel{\mathbb{\Omega}}{\varrho}$ of the study suggests that the diffusion findings should be considered in relation to the preceding $\vec{P}$ changes in the lungs. The natural history and prognosis of patients with pulmonary sarcoidosis $\vec{\omega}$ have been analysed by Hoyle (1961). He classified 9 125 patients into three main groups which together $\overrightarrow{\vec{x}}$ form a spectrum of the disease (Fig. 9). Group $\mathrm{I} \dot{\infty}$

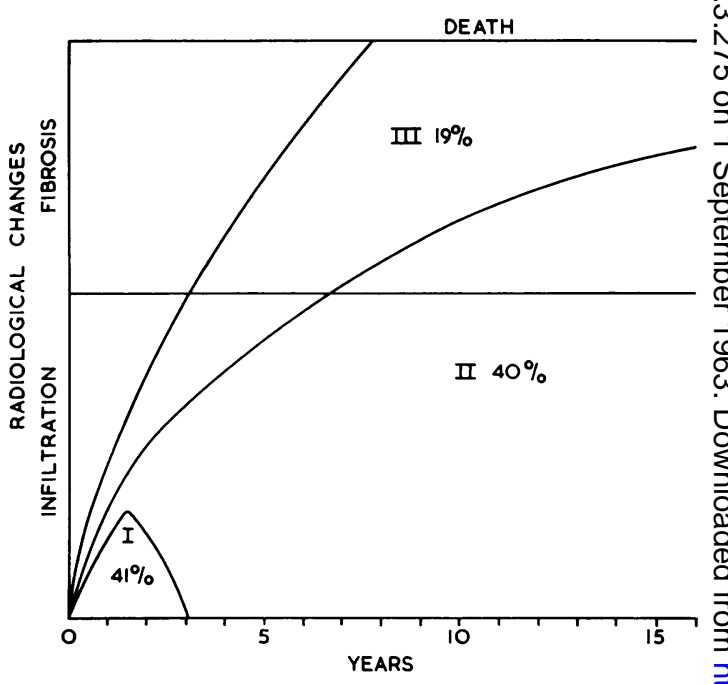

FIG. 9. Classification of sarcoidosis proposed by Hoyle (1961). The diagram correlates the radiographic changes with the duration of the disease.

consisted of $41 \%$ of the patients, in whom $\frac{0}{3}$ pulmonary infiltration was transient, the chest radiograph becoming normal within about two years. Group II formed $40 \%$ of the total and was made up of patients in whom pulmonary infiltra-은 tion persisted but did not increase progressively, $D$ so that eventual fibrosis was not severely destructive. The remaining $19 \%$ of subjects were classed as group III ; they showed progressive? infiltration followed by severe radiological fibrosis $N$ leading to dyspnoea and heart failure.

The five patients studied here who showed resolution of previous pulmonary infiltration fall into group I of this classification. In three of these $\frac{\vec{D}}{\mathbb{D}}$ patients an abnormality of DM persists in spite of radiological clearing. A similar persistence of $\square$ impaired DL has been reported by Marshall et al.

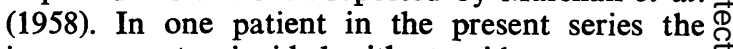
improvement coincided with steroid treatment, so $\underset{\mathbb{Q}}{\mathbb{Q}}$ radiological clearing following such therapy cannot 
be taken to indicate a corresponding resolution of the pathological changes in the lungs.

Three patients with pulmonary infiltration of short duration had normal diffusion. In the patients with pulmonary infiltration for more than a few years there was always a reduction in DM, and in some of those with changes for more than five years the Vc was also reduced. It seems likely that this is the course followed by the patients in group II of Hoyle's (1961) classification. A tendency to more severe changes in overall diffusing capacity (DL) when radiographic abnormalities have been present for more than a few years is reported by Marshall et al. (1958) and by Stone et al. (1953).

The absence of changes in diffusion with pulmonary infiltration of relatively short duration suggests that the pathological changes responsible for the radiographic shadows may differ during the course of the disease. Though deposits of sarcoid tissue might be expected to increase the thickness of the alveolar-capillary membrane, they do not seem to interfere significantly with gas transfer at first. In fact, the scattered sarcoid follicles probably leave large areas of the diffusion pathway unimpaired (Longcope and Freiman, 1952). The reduction in DM found in cases with pulmonary infiltration for more than two or three years might then be attributed to a critical increase in the sarcoid deposits interfering with gas transfer. However, there is no corresponding increase in the density of the radiographic changes.

The reduction in DM after several years of pulmonary infiltration may be attributable to fine fibrotic changes not evident in the radiograph but reducing the area available for diffusion. The progressive impairment of the membrane component over the years may be explained in this way. An alternative possibility is that the $D M$ is determined only in part by the physical process of diffusion in the alveolar-capillary membrane and is in the main an index of uneven distribution of ventilation and perfusion in the lung (Asmussen and Nielsen, 1960 ; Staub, 1961 ; Chinard, Enns, and Nolan, 1961). The absence of changes early in the course of pulmonary infiltration would not be unexpected in these circumstances, and the later deterioration might be attributed to the distorting effects of fine fibrosis.

Reduction of the Vc appears to be confined to patients with long-standing disease. It was not found in the absence of a reduction in DM, and may indicate a more severe degree of diffuse fibrosis, not necessarily evident radiologically.
However, these subjects show no greater change in DM than those with a normal Vc, suggesting that a different mechanism is involved. A predominantly perivascular distribution of the sarcoid follicles (Longcope and Freiman, 1952) may be responsible. Marshall et al. (1958) suggest that the impairment of diffusion in pulmonary sarcoidosis is mainly due to perivascular lesions, as the mechanical properties of the lungs are relatively little affected. The reduced Vc found in one patient by Bates et al. (1960) is further support for this hypothesis.

The four patients with considerable radiological resolution but persistent local fibrosis show relatively little change in diffusion considering the long history of lung disease. Two have in fact normal diffusion measurements. These findings indicate that local fibrosis has little effect on diffusion, the relatively unaffected lung tending to predominate. Both Marshall and his colleagues (1958) and Svanborg (1961) report normal values for overall diffusing capacity (DL) in a few patients with only minor signs of fibrosis.

The patients with radiological evidence of pulmonary fibrosis have serious long-standing disease and correspond to group III of Hoyle's (1961) classification. The changes in diffusion, however, are similar to those found in patients with a long history of pulmonary infiltration without fibrosis. Although all the patients with radiological fibrosis were known to have had radiographic changes for more than five years and had an impaired DM, only half showed reduction in Vc. The changes in the radiographs interpreted as pulmonary fibrosis are mainly confined to the upper lobes, and there is often apparent overdistension of the lower lobes. Relatively normal function in these regions may account for the lack of correlation between the radiological evidence of fibrosis and the reduction of Vc. Svanborg (1961) found evidence of an increased gravitational shift of blood to the legs in many patients with pulmonary sarcoidosis, which might be expected to reduce the $\mathrm{Vc}_{\mathrm{c}}$ and $\mathrm{DL}_{\mathrm{L}}$; however, measurement of DL, sitting and supine, in three cases is reported as showing little change.

As the Vc was not reduced without serious impairment of $D_{M}$ in the present study, the $D_{L}$ gave a good indication of the severity of the disease. Nevertheless, a study of the components of the diffusing capacity can give helpful additional information at times. In two subjects (P.J. and H.B.) a significant reduction in DM was accompanied by an unusually large Vc, so that the DL was normal. Similarly, measurement 
of $D_{L}$ cannot detect the stage at which the Vc begins to fall. This may be a critical point in the progress of the disease as it suggests that the pulmonary vascular bed is becoming seriously damaged.

EFFECTS OF STEROID THERAPY Studies before and during steroid therapy in three subjects with pulmonary infiltration but no radiological fibrosis showed little improvement in the diffusion changes in spite of some clearing of the radiographic shadows in the two cases with shorter histories. Another patient (J.S.) developed a normal chest film on steroid therapy, but an abnormality of diffusion persisted. In the remaining seven patients studied during steroid therapy pulmonary infiltration had not cleared, and there was radiological evidence of fibrosis in all but two ; serious impairment of diffusion was found in these patients.

An increase in lung volumes has been reported frequently following steroid therapy in pulmonary sarcoidosis (Small, 1951; Riley et al., 1952; Shulman et al., 1952 ; Stone et al., 1953 ; RudbergRoos and Roos, 1958), as in spontaneous resolution (Bruce and Wassén, 1940), but Riley et al. (1952) found no increase in diffusing capacity for oxygen after A.C.T.H. therapy in three patients, and McClement et al. (1953) found improvement in only one of four cases treated with cortisone. Smellie, Apthorp, and Marshall (1961) studied the effect of steroid therapy in six patients with sarcoidosis and abnormal pulmonary function, and found some improvement in lung volume and diffusing capacity, but the values did not reach normal levels.

The results in these few cases suggest that though pulmonary infiltration of short duration clears during steroid therapy much of the effect on diffusion persists. This is consistent with the suggestion that the impairment of diffusion is due to fine fibrotic changes which would be expected to remain after resolution of the exudative components of the sarcoid granulomata on steroid therapy. Biopsies have shown a change from a granulomatous to a fibrotic lesion during treatment with steroids (McClement et al., 1953), tending to support this view.

\section{CONCLUSION}

The changes in the diffusion process found in patients with pulmonary sarcoidosis are probably due to diffuse fibrosis. Although individual patients were not studied throughout the course of the disease, an overall picture of the changes in diffusion can be built up from the separate case reports. No abnormality of diffusion is found with pulmonary infiltration of short duration, but after one to three years the membrane component (DM) becomes impaired. This component (DM) falls progressively during the subsequent three to five years if pulmonary infiltration persists, but there is little further deterioration after this time. In half the patients with pulmonary infiltration for more than five years the pulmonary capillary volume $(\mathrm{Vc})$ becomes reduced.

Although these changes are interpreted as $\underset{\omega}{\infty}$ evidence of fibrosis there is little correlation with iv the conventional radiological signs of fibrosis, and $\mathrm{v}$ subjects with radiographic changes confined to one $\frac{\rho}{3}$ upper lobe show only minor changes in diffusion. $\rightarrow$ The radiological appearances probably indicate $\mathcal{D}$ local effects whereas the diffusion findings are determined by diffuse changes throughout the lungs.

It seems likely that diffusion measurements will prove to be complementary to radiological $\vec{\oplus}$ examination in assessing the progress and $\stackrel{\circ}{\circ}$ prognosis of patients with pulmonary sarcoidosis, and that measurement of the two components of diffusion will be helpful in defining the changes in the lungs more precisely than is possible from the overall diffusing capacity.

I am grateful to Dr. Clifford Hoyle for his encouragement and advice in carrying out this work, and for permission to study patients under his care.

\section{REFERENCES}

Asmussen, E., and Nielsen, M. (1960). Alveolo-arterial gas exchange at rest and during work at different $\mathrm{O}_{2}$ tensions. Acta physiol. scand., $50,153$.

Austrian, R., McClement, J. H., Renzetti, A. D., Donald, K. W., Riley, R. L., and Cournand, A. (1951). Clinical and physiologic features of some types of pulmonary diseases with impairment of alveolar-capillary diffusion: the syndrome of " alveolar-capillary block." Amer. J. Med., 11, 667.

Baldwin, E. deF., Cournand, A., and Richards, D. W. (1949). Pulmonary insufficiency II. A study of thirty-nine cases of pulmonary $\frac{D}{2}$

Bates, D. V. (1958). The measurement of the pulmonary diffusing capacity in the presence of lung disease. J. clin. Invest., 37, 591. N Varvis, C. J., Donevan, R. E., and Christie, R. V. (1960). O Variations in the pulmonary capillary blood volume and membrane diffusion component in health and disease. Ibid., 39, 1401. N

Bruce, T., and Wassén, E. (1940). Clinical observations on the course and prognosis of lymphogranulomatosis benigna Schaumann, $\omega$

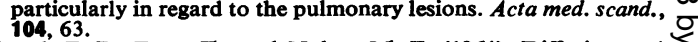
Chinard, F. P., Enns, T.. and Nolan, M. F. (1961). Diffusion and solubility factors in pulmonary inert gas exchanges. $J$. appl. $\frac{\mathrm{C}}{\mathrm{C}}$
Physiol., 16, 831.

Coates, E. O., and Comroe, J. H. (1951). Pulmonary function studies

Forster, R. E., Roughton, F. J. W., Cander, L., Briscoe, W. A., and T Kreuzer, F. (1957). Apparent pulmonary diffusing capacity for $\mathrm{CO}$ at varying alveolar $\mathrm{O}_{2}$ tensions. J. appl. Physiol., 11, 277 .

Gray, F. D., and Gray, F. G. (1957). Pulmonary sarcoidosis: a $\frac{\vec{D}}{(19}$ physiopathologic analysis. J. chron. Dis., 6, 572 .

Hamer, N. A. J. (1962). The effect of age on the components of the $\stackrel{\overparen{D}}{\text { physiopathologic }}$ pulmonary diffusing capacity. Clin. Sci., 23,85 .

Hoyle, C. (1961). Prognosis of pulmonary sarcoidosis. Lancet, 2, 611. 它 
Johnson, R. L., Lawson, W. H., and Wilcox, W C. N. (1961). Alveolar capillary block in sarcoidosis. Clin. Res., 9 , 196.

Jones, R. S., and Meade, F. (1961). A theoretical and experimental analysis of anomalies in the estimation of pulmonary diffusing capacity by the single breath method. Quart. J. exp. Physiol., 46, 131 .

Krogh, M. (1915). The diffusion of gases through the lungs of man. J. Phisiol. (Lond.), 49, 271.

Leitner, St. J. (1946). Elektrokardiographische und spirometrische Untersuchungen bei der epitheloidzelligen Granulomatose Untersuchungen bei der epitheloidzelligen Granulomatose
(Morbus Besnier-Boeck-Schaumann).Cardiologia(Basel), 10,379.

Longcope, W. T., and Freiman, D. G. (1952). A study of sarcoidosis based on a combined investigation of 160 cases including 30 autopsies from the Johns Hopkins Hospital and Massachusetts General Hospital. Medicine (Baltimore), 31, 1 .

McClement, J. H., Renzetti, A. D., Himmelstein, A., and Cournand, A. (1953). Cardiopulmonary function in the pulmonary form of Boeck's sarcoid and its modification by cortisone therapy. Amer. Boeck's sarcoid and its
Rev. Tuberc., 67, 154.

McGrath, M. W., and Thomson, M. L. (1959). The effect of age, body size and lung volume change on alveolar-capillary permeability and diffusing capacity in man. J. Physiol. Lond., 146, 572.

McNeill, R. S., Rankin, J., and Forster, R. E. (1958). The diffusing capacity of the pulmonary membrane and the pulmonary capillary blood volume in cardiopulmonary disease. Clin. Sci. capillary

Marshall, R., and DuBois, A. B. (1956). The viscous resistance of lung tissue in patients with pulmonary disease. Ibid., 15, 473 .

Smellie, H., Baylis, J. H., Hoyle, C., and Bates, D. V. (1958). Pulmonary function in sarcoidosis. Thorax, 13,48 .

Morrison, C., Fulton, J., and Hickam, J. B. (1957). Ventilatory function in pulmonary sarcoidosis. Clin. Res. Proc., 5, 119.

Needham, C. D., Rogan, M. C., and McDonald, I. (1954). Normal standards for lung volumes, intrapulmonary gas-mixing, and maximum breathing capacity. Thorax, 9,313 .

Ogilvie, C. M., Forster, R. E., Blakemore, W. S., and Morton, J. W. (1957). A standardized breath holding technique for the clinical measurement of the diffusing capacity of the lung for carbon monoxide. J. clin. Invest., 36, 1.
Riley, R. L., Riley, M. C., and Hill, H. McD. (1952). Diffuse pulmonary sarcoidosis: diffusing capacity during exercise and other lung function studies in relation to ACTH therapy. Bull. Johns Hopk. Hosp., 91, 345.

Roughton, F. J. W., and Forster, R. E. (1957). Relative importance of diffusion and chemical reaction rates in determining rate of exchange of gases in the human lung, with special reference to true diffusing capacity of pulmonary membrane and volume of blood in the lung capillaries. J. appl. Physiol., 11, 290.

Rudberg-Roos, I., and Roos, B. E. (1958). Pulmonary function in sarcoidosis before and after ACTH and cortisone therapy. Acta tuberc. scand., 35, 49.

Shulman, L. E., Schoenrich, E. H., and Harvey, A. McG. (1952). The effects of adrenocorticotropic hormone (ACTH) and cortisone on sarcoidosis. Bull. Johns Hopk. Hosp., 91, 371.

Siösteen, S. M., and Sjöstrand, T. (1951). A method for the determination of low concentrations of $\mathrm{CO}$ in the blood and the relation between the $\mathrm{CO}$-concentration in the blood and that in relation between the CO-concentration in the
the alveolar air. Acta physiol. scand., 22, 129.

Small, M. J. (1951). Favorable response of sarcoidosis to cortisone treatment. J. Amer. med. Ass., 147, 932.

Smellie, H., Apthorp, G. H., and Marshall, R. (1961). The effect of corticosteroid treatment on pulmonary function in sarcoidosis. Thorax, 16, 87.

- and Hoyle, C. (1960). The natural history of pulmonary sarcoidosis. Quart. J. Med., n.s. 29, 539.

Staub, N. C. (1961). Is there ever a measurable alveolar-arterial $\mathbf{O}_{2}$ gradient due to diffusion? Physiologist, 4, 115.

Stone, D. J., Schwartz, A., Feltman, J. A., and Lovelock, F. J. (1953). Pulmonary function in sarcoidosis: results with cortisone therapy. Amer. J. Med., 15, 468.

Svanborg, N. (1961). Studies on the cardiopulmonary function in sarcoidosis. Acta med. scand., 170, suppl. 366, pp. 7, 34, and 75.

Thews, G., and Niesel, W. (1959). Zur Theorie der Sauerstoffdiffusion im Erythrocyten. Pfiügers Arch. ges. Physiol., 268, 318.

Williams, M. H. (1953). Pulmonary function in Boeck's sarcoid. $J$. clin. Invest., 32, 909.

Yahr, W. Z., and Kreuzer, F. (1960). Influence of red cell membrane on $\mathrm{O}_{2}$ diffusion. Fed. Proc., 19, 382. 